\title{
Pseudoparabolic inequalities
}

\section{CECILIA CRĂCIUN and N. LUNGU}

\section{ABSTRACT.}

In this paper we apply the Picard operators technique to a pseudoparabolic inequality. We establish existence and uniqueness of the solution to the corresponding Darboux problem, and derive Gronwall-type results for the solution to the pseudoparabolic inequality. We use the Riemann function to represent the solution $x^{*}$ of some particular pseudoparabolic equations.

\author{
COLFE'S SCHOOL \\ HORN PARK LANE \\ LONDON, SE12 8AW, UNITED KINGDOM \\ E-mail address: ceciliacraciun@yahoo.com \\ TECHNiCAL UNIVERSITY OF CLUJ-NAPOCA \\ DEPARTMENT OF MATHEMATICS \\ C. Daicoviciu 15, 400020 Cluj-Napoca, Romania \\ E-mail address: nlungu@math.utcluj.ro
}

Received: 22.03.2010; In revised form: 12.05.2011; Accepted: 30.06.2011

2010 Mathematics Subject Classification. 35K70.

Key words and phrases. Pseudoparabolic inequalities, abstract Gronwall Lemma, Picard operators, Riemann function. 